\title{
Reorientation of lineation in the Central Crystalline Zone, Munsiari-Milam area of the Kumaun Greater Himalaya
}

\author{
A K Verma and A R Bhattacharya* \\ Centre of Advanced Study in Geology, University of Lucknow, Lucknow 226 007, India. \\ ${ }^{*}$ Corresponding author. e-mail: arb65k@rediffmail.com
}

During large scale ductile shear deformation, linear features of the rocks tend to be reoriented towards the direction of bulk shear. This is demonstrated in a crustal scale shear zone of the Himalaya, the Main Central Thrust (MCT), typically exposed in the Munsiari-Milam area of eastern Kumaun Greater Himalaya. Along the MCT, the crystalline rocks of the Greater Himalaya are thrust over the younger sedimentary belt of the Lesser Himalaya. In the study area, the scatter of lineation orientation in the vicinity of the MCT has been observed to drastically reduce within $27^{\circ}$ in a zone of about $18 \mathrm{~km}$ (about $13 \mathrm{~km}$ in the crystalline rocks and about $5 \mathrm{~km}$ in the sedimentary rocks). Beyond this zone, the scatter is very high, up to $70^{\circ}$ or more. The low scatter of lineation orientation around the MCT could be related to the strong ductile shear deformation associated with the movement along this thrust due to which the linear features got reoriented towards the direction of bulk shear. Away from this zone, ductile shearing had negligible or no effect on the rocks and, therefore, the scatter of lineation remains very high.

\section{Introduction}

Most ductile shear zones show the development of a variety of linear structures developed in the plane of foliation. In most cases, the geometry and orientation of the linear structures show variation in space and time. Of special interest is the phenomenon of reorientation of pre-shearing linear structures during progressive simple shear. It is only during the seventies that this aspect has drawn the attention of structural geologists. Ramberg and Ghosh (1977) were some of the earlier workers who presented a theoretical model of rotation and strain of linear and planar structures in homogeneous, three-dimensional progressive deformation. They assumed that the initial marker lines and the principal strain axes remain in their original plane during the deformation and that the markers and the principal axes, due to variation in their rotation rates, will generally not coincide during the continued deformation. It is only after a very large homogeneous deformation, the long principal axis and its initial marker lines tend to become parallel again. The Ramberg-Ghosh model thus provides a basis for the study of rotational behaviour of material lines contained in competent layers of rocks embedded in less competent layers.

In about the last three decades, a large number of shear zones have been studied from various angles by different researchers from all over the world. As a result, a variety of information on the nature of rotation of marker objects has come to light. Bell (1978), with the example of Woodroffe thrust, has demonstrated that linear structures (mainly fold axes) that are initially formed at approximately $90^{\circ}$ to mineral elongation have rotated with increase in strain towards the main thrust. Skjernaa (1980) presented a mathematical solution of how the preshear zone planes and lines undergo reorientation

Keywords. Stretching lineation; ductile shear deformation; Greater Himalaya; Main Central Thrust. 
and deformation during formation of a shear zone by simple shear. It has been suggested that during progressive simple shear, while a layer parallel to $\mathrm{XY}$ plane gets extended in X-direction, it is shortened parallel to Y-direction. To accommodate this shortening, the material lines reorient themselves in the direction of bulk shear. According to Sanderson and Marchini (1984), the fold axes may rotate towards the shear plane with increasing strain, but high shear strain is necessary to reduce this angle to $<22.5^{\circ}$. Almost a similar opinion has also been put forward by Ridley (1986) who suggested that rotation of fold axes into parallelism with the slip and extension direction in a rock may take place when the spatial variation in shear strain in a ductile shear zone is perpendicular to the displacement direction. Aubourg et al. (1991) studied the magnetic fabric of the Callovian-Oxfordian black of French Alps and have shown that the stretching lineation exhibits a rotation as a result of shear deformation.

Rotation of material objects during shear deformation has also been viewed from theoretical angles. Mandal et al. (2005) presented a theoretical model of rotation of elliptical rigid inclusions hosted in a foliated matrix. They suggested that during deformation, the sense of instantaneous rotation is dependent on the inclination of the foliation plane to the long axis of inclusion $(\theta)$; with increase in $\theta$, the sense of instantaneous rotation reverses at a critical value of $\theta$.

In recent years, due to improvement in numerical techniques, the problem of rotation of material objects during progressive simple shear deformation has added some new dimensions. Griera et al. (2013) suggest that anisotropic rheology is a primary factor in the rotation as well as the rotation rate of material objects during non-coaxial deformation.

In the Himalayan domain, however, work on reorientation of lineation as a result of ductile shearing is almost absent. Le Fort (1975) and Schakleton and Ries (1984) had mentioned the presence of a strong $\mathrm{N}-\mathrm{S}$ oriented lineation almost for the entire Himalayan region and they linked this lineation alignment to the northward motion of the Indian plate. Brunel (1986) described stretching lineation from parts of NW Himalaya and related it to ductile thrusting of the crystalline masses. Bhattacharya and Weber (2004) made a detailed study of quartz c- and $\langle a\rangle$ axis fabrics of the MCT zone of the Kumaun and Garhwal sectors along with some relevant microstructures and stretching lineations. In this study, although it has been mentioned that the crystalline rocks of the higher horizons of the Greater Himalaya show mineral lineations, the lower horizons, i.e., the vicinity of the MCT, are characterized by stretching lineations.
However, there is no discussion on the rotational nature of lineation for the crystalline mass. Thus in the Himalayan region, practically no work is available as yet on the rotation of lineation in shear regime.

To summarise, the literature on reorientation of linear structures and marker objects in simple shear regime reveals that the subject has been viewed from several angles, viz., experimental deformation, numerical simulation, mathematical modelling, and field and microstructural data. Also, each shear zone has its own geological, lithological, and tectonic settings. As such, no shear zone can be compared with others. Possibly because of this, the results obtained from different methods do not lead to a single conclusion and, therefore, every shear zone may have its own specific model under a broader framework.

Keeping all these in mind, we have provided inputs from field data for the MCT zone in this paper. Our work reveals that azimuthal values of lineation orientation hold good potential for working out a model for the MCT zone of the study area. We have observed the occurrence of a zone showing low scatter of lineation orientation in the vicinity of the MCT and a zone of high scatter outside this zone. We link this low scatter to the proximity of the thrust and conclude that at high ductile shear strains, lineations tend to reorient themselves in the direction of bulk shear. Quantitative demonstration of lineation reorientation, as presented in this paper, has not yet been done for the Himalayan region. This automatically speaks of the high significance of the work in the Himalayan context.

\section{Geological set-up}

The Kumaun Himalaya represents all the four major lithotectonic subdivisions (figure 1) of the Himalaya (Gansser 1964), from S to N, these are: (1) Outer Himalaya that is mainly represented by Siwalik Supergroup (Upper Tertiary) rocks and their equivalents, and is bound to the north by the Main Boundary Thrust (MBT) and by the Himalayan Frontal Thrust to the south. (2) Lesser Himalaya constitutes a widespread sedimentary belt of upper Precambrian ages together with a few outcrops of ancient crystalline-metamorphic rocks that are believed to have come to rest by tectonic transport from the Greater Himalayan crystalline zone; southern boundary of this subdivision is the MBT while the northern boundary is called the Main Central Thrust (MCT). (3) Greater Himalaya exposes a persistently northdipping thick pile of crystalline-metamorphic rocks that are bound to the south by the MCT and 


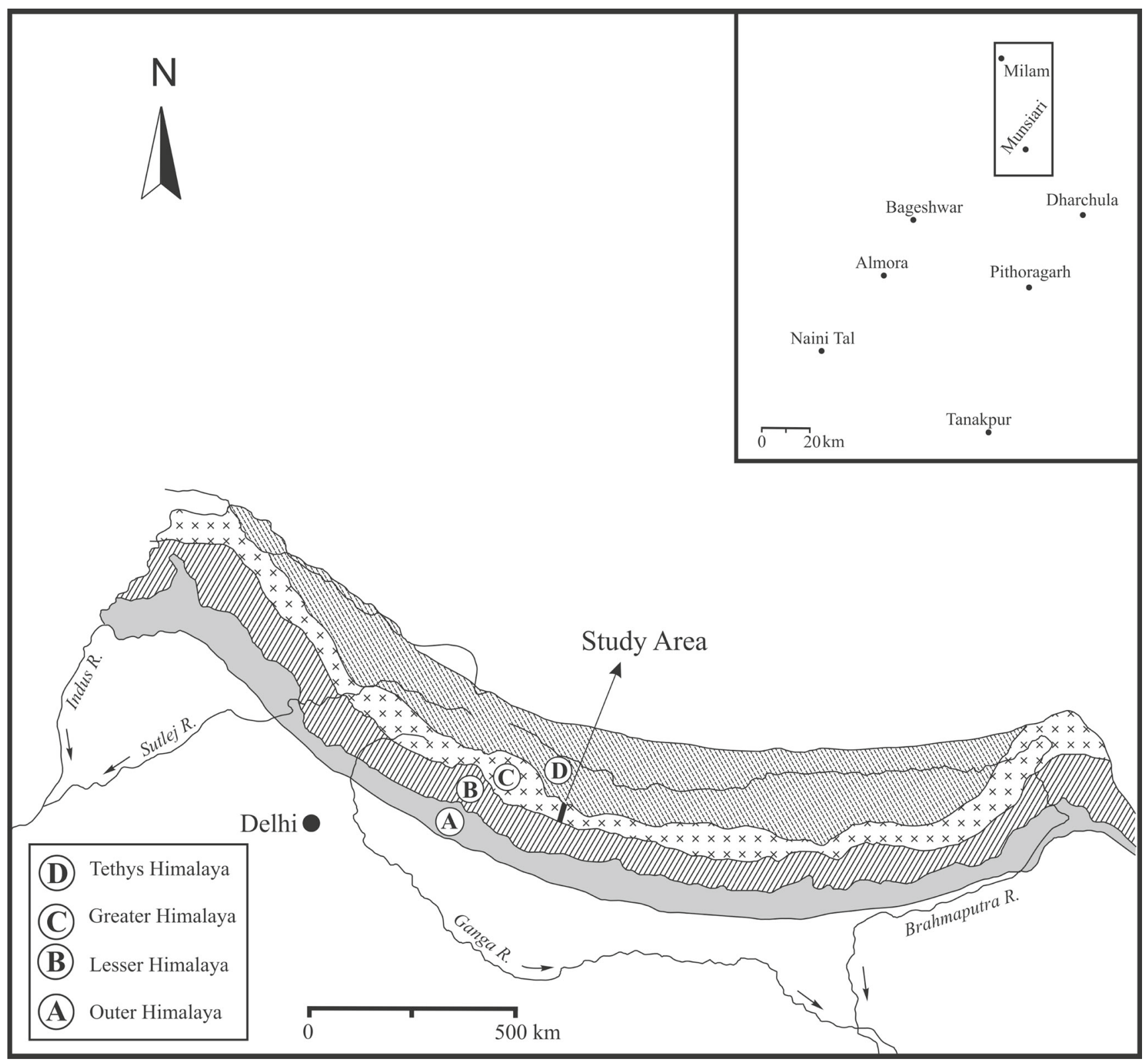

Figure 1. Geological sketch map of the Himalaya (after Gansser 1964) showing the study area. A: Outer Himalaya, B: Lesser Himalaya, C: Greater Himalaya, D: Tethys Himalaya. An index map of the Kumaun Himalaya has been provided on the top right corner showing the study area.

by the Martoli Fault (MT) or the South-Tibetan Detachment to the north. (4) Tethys Himalaya that shows a massive pile of sedimentary rocks of Cambrian to Lower Eocene ages and is bounded by the Dar-Martoli Fault to the south and by the Indus Suture Zone to the north.

This paper incorporates a study of the lineation pattern in the crystalline rocks of the Greater Himalaya in the Munsiari-Milam transect of the eastern Kumaun Himalaya. The area exposes a massive pile of medium to high grade crystallinemetamorphic rocks called the Central Crystalline Zone (CCZ). The CCZ is tectonically delimited to the south by the MCT against the sedimentary belt of the Lesser Himalaya. To the north, the crystalline zone is juxtaposed against the sedimentary belt of the Tethys Himalaya and the contact is defined by the Martoli Fault.

The study area constitutes a very rugged and difficult terrain in the far interiors of the northeast Kumaun Himalaya and falls in the Pithoragarh district. The northern part of the area is occupied by the famous Milam glacier. Different parts of the area are reached on foot only along some bridle paths, if any, or by trekking. Since the area falls in the snowy belt, it is free from vegetation, except around Munsiari where a thick cover of vegetation is present. 
As yet, the area has drawn very little attention from geologists. The first available geological information of the area can be seen in the work of Heim and Gansser (1939) and Gansser (1964). Misra and Bhattacharya (1976) presented a generalized work on the central crystalline of the Greater Himalaya of the Kumaun region. Bhattacharya (1982), while describing the geology of the area around Tejam and Girgaon areas, made a reference of the area around Munsiari. Bhattacharya and Siawal (1985) mapped the western adjoining Tejam-Namik area and worked out the structural geology, especially the folding pattern, of the rocks. Patel and Kumar (2009) presented the lithology and metamorphism of the rocks of the Goriganga valley. Moharana et al. (2013) studied deformation style in the Madlakia-Munsiari-Dhapa section. It thus appears that as far as the Munsiari-Milam tract is concerned, detailed structural studies are still lacking. With this background, the authors have attempted a systematic structural study of the area. Of the various structural features shown by the rocks of the area, the authors have observed some interesting aspects on the orientation pattern of lineation as described in the present paper.

The area exposes a massive pile of crystalline metamorphic rocks belonging to the CCZ (Heim and Gansser 1939; Gansser 1964) of the Greater Himalaya. The major rock types include gneisses, augen gneisses, mylonites, quartzites, granites, and a variety of schists. In the higher horizons to the farther north, the sequence shows intrusions (dykes and veins) of acid igneous rocks, mainly granites, tourmaline-bearing granites, aplites and quartzofeldspathic veins. Typically these granites/aplites do not show foliation or any imprints of internal deformation, thus suggesting their emplacement very late in the geological-structural evolution of the CCZ.

The CCZ in this sector has been lithologically subdivided into three units. It may be mentioned here that since the area is almost uninhabited by people, no specific name of these units after the name of a place can be assigned to these units and they are, therefore, informally referred to here as Unit I, II and III. The lower unit (Unit I) is represented by mylonites and mylonitic gneisses. The middle unit (Unit II) is constituted of gneiss, augen gneiss, granitic gneiss, muscovite gneiss, and biotite gneiss. The upper unit (Unit III) is represented by muscovite schist, garnetiferous mica schist, quartzbiotite schist and quartzite. This Unit III also typically shows numerous veins, lenses and smaller dykes of aplite, granite and tourmaline leucogranite as mentioned above; typically all these igneous bodies are non-foliated suggesting a later acid igneous activity after the metamorphism of Unit III in particular and possibly after the metamorphism of the entire crystalline zone of the Greater Himalaya.

\section{Structural set-up}

The foliation of the rocks of the study area persistently dips northwards. This suggests that the structure of the crystalline zone is a homocline (figure 2). Locally the dip of foliation varies from NW to ENE, from $10^{\circ}$ to $60^{\circ}$. The entire sequence of rocks seems to show a monotonous structure practically without any noticeable local change in structure. However, structural complexities are noticed in the vicinity of the Martoli Fault only, e.g., random changes in dip and strike of the rocks,

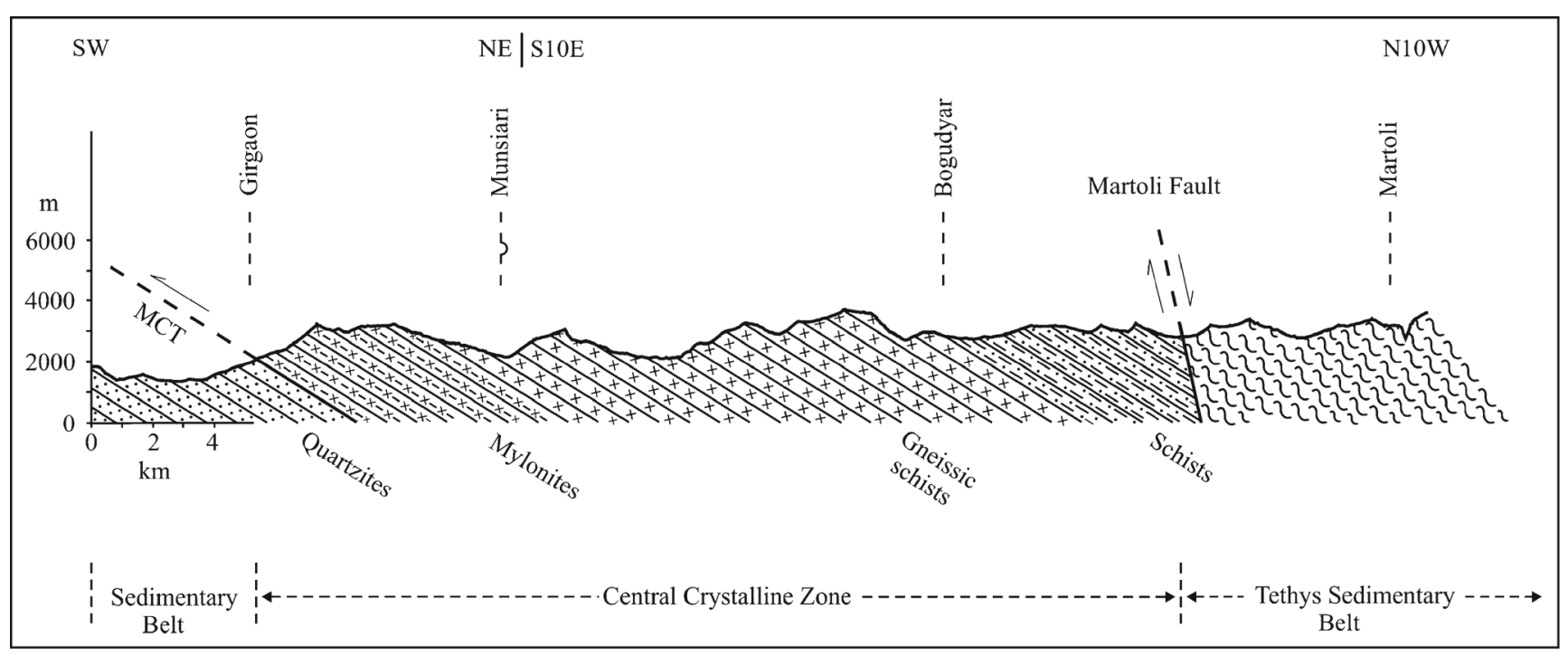

Figure 2. Geological cross-section showing the structure of the rocks of the area. 


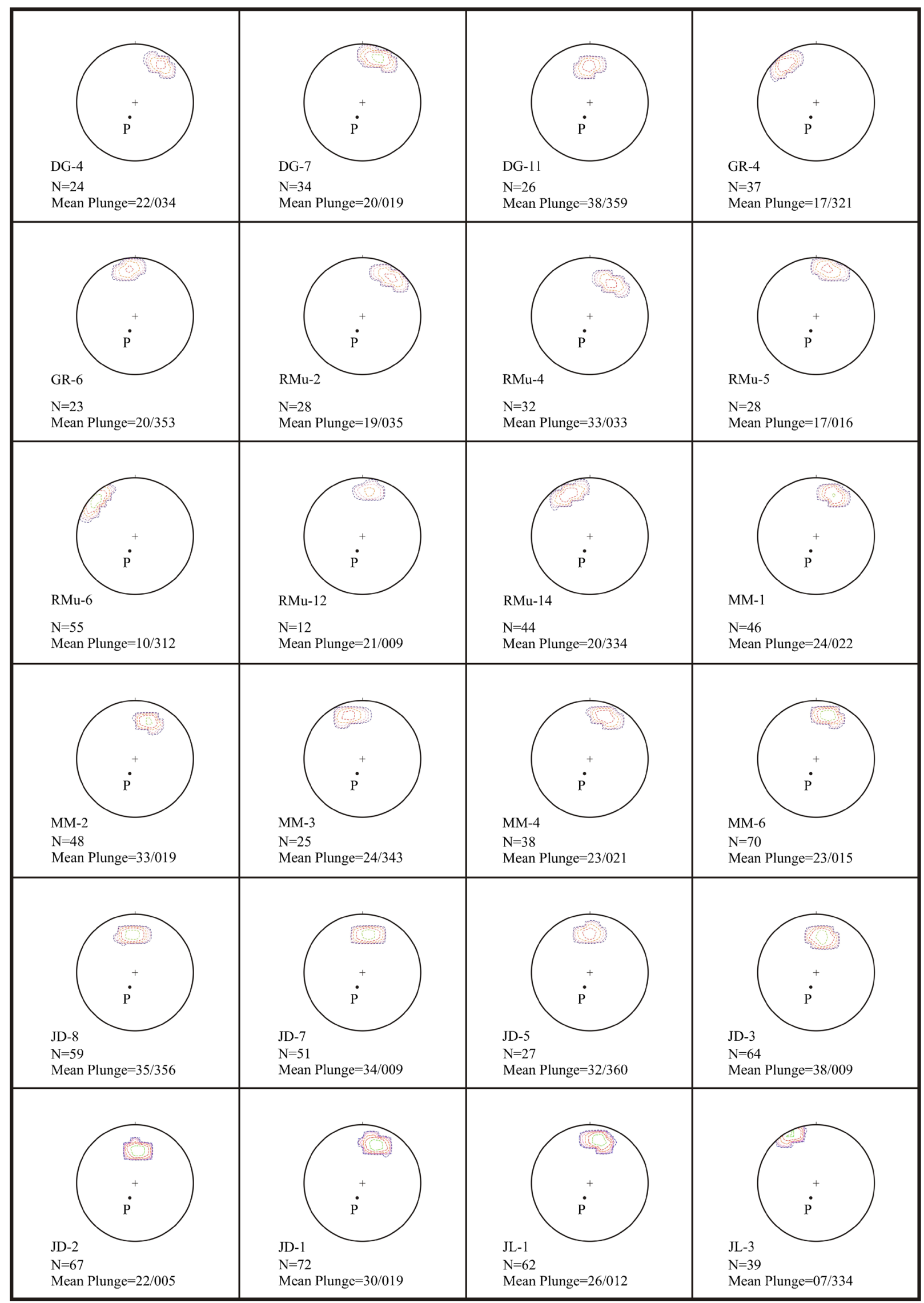

Figure 3. Stereo-plots showing the attitude of lineation in the samples as studied in the present work. In the stereo-plots, $\mathrm{P}$ represents the pole of the mean MCT plane. 


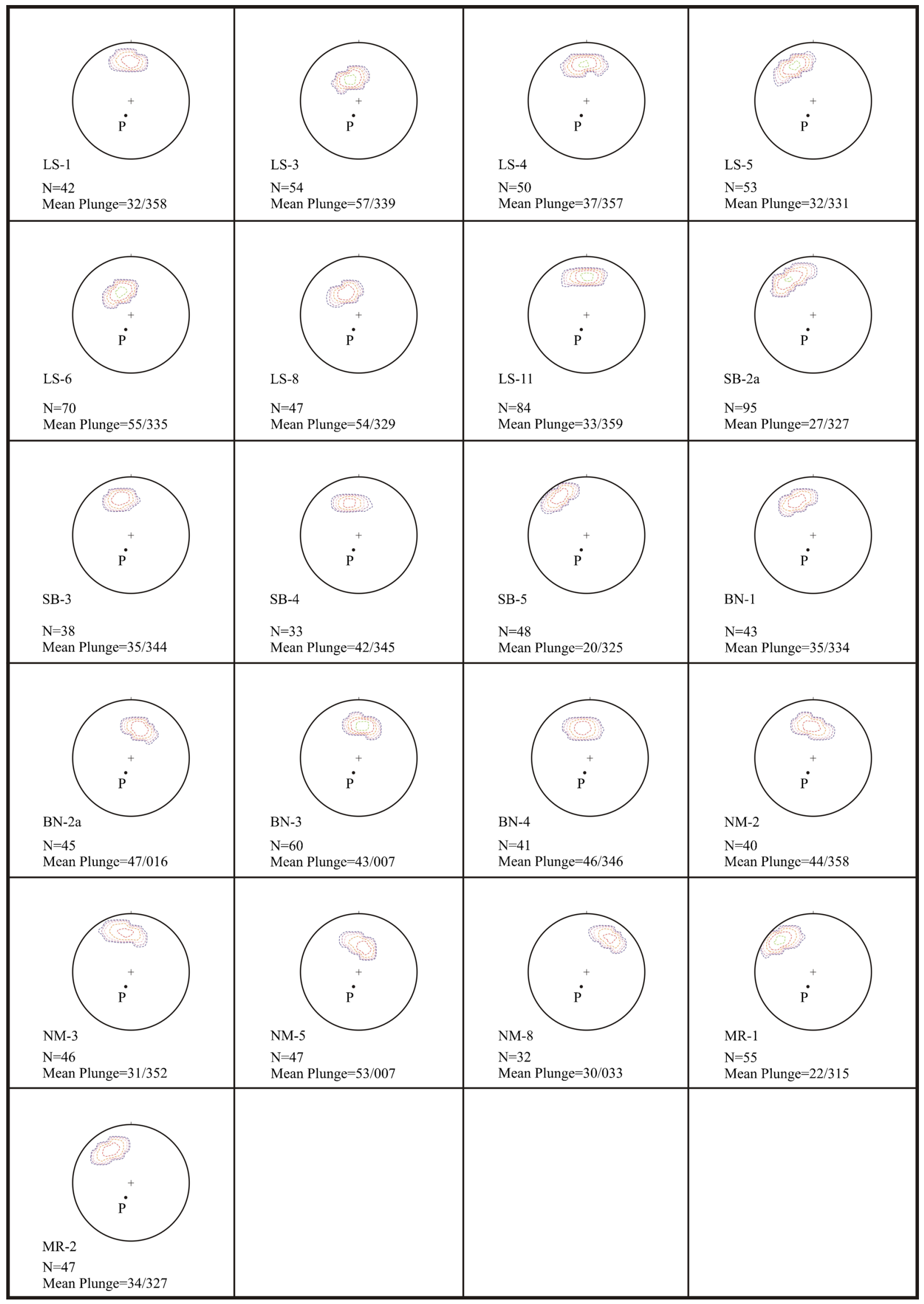

Figure 3. (Continued.) 
local development of fault scarps, small scale (synthetic) faults, silicification, crushing, etc. All these features are noticed in the rocks of the crystalline zone as well as those of the Tethys zone.

In general, the lower unit is dominated by mylonites, the middle unit by gneissic rocks and the upper unit by schistose rocks. As such, the rocks of the lower unit are characterized by a tectonic (mylonitic) foliation while those of the higher units by lithological or metamorphic foliation.

\section{Lineation pattern}

Occurrence of lineation is a common feature of the rocks of the CCZ. Lineation in the rocks of the higher horizons (Units II and III) could be considered as structural lineations represented by preferred orientation of linear features formed from the planar features during deformations (Twiss and Moores 1992, p. 274). These lineations may have formed prior to the MCT emplacement and have been named here as $\mathrm{L}_{1}$ and mainly include alignment of platy and flaky minerals such as hornblende, tourmaline, and micaceous minerals. The lineations developed in the lower horizons (Unit I), on the other hand, are represented by stretched porphyroclasts, elongated trails of quartz and quartzo-feldspathic minerals and stretched mica aggregates, and as such could be considered as stretching lineations formed at depth during the strong ductile deformation associated with the movement of the crystalline mass along the MCT. That is why these lineations are confined to the vicinity of the MCT and have been named here as $\mathrm{L}_{2}$. The $\mathrm{L}_{2}$ lineations progressively become stronger towards the trace of the MCT from both the up-thrust (crystalline rocks) and sub-thrust (sedimentary rocks) blocks. Further, in addition to stretching lineations, Unit-I also shows some mineral lineations given by muscovite, biotite and hornblende. These lineations, like stretching lineations, also show low scatter up to $27^{\circ}$ and are therefore included under $\mathrm{L}_{2}$ lineation. Since lineations shown by muscovite and biotite are also present in the upper units of the crystalline zone where they show high scatter (up to $70^{\circ}$ and even more), it is possible that $\mathrm{L}_{2}$ mineral lineations of Unit-I represent the rotated counterparts of the $\mathrm{L}_{1}$ lineations. This further strengthens the fact that material lines have been reoriented due to movements associated with the MCT.

Because of intense shear deformation associated with the MCT, stretching lineations are also developed in the rocks situated at the top of the sedimentary belt in the vicinity of the MCT. In the sedimentary belt, the rock types in the vicinity of the MCT mainly include quartzite, sericite quartzite, and marble. All these rocks up to a distance of $3-4 \mathrm{~km}$ from the trace of the MCT prominently show stretching lineation shown by the stretching of quartzo-feldspathic mineral aggregates and stretched trails of recrystallized quartz. The lineations in the sedimentary rocks located further south of this distance can be described as structural lineation (see Twiss and Moores 1992, p. 274).

Attitude of lineation has been systematically measured in the crystalline rocks from the base to the top of the crystalline zone, while in sub-thrust block (sedimentary belt) up to about $5 \mathrm{~km}$ only because beyond this distance the effect of MCT in reorienting the lineation pattern is not observed. The amount and direction of plunge have been noted and plotted on stereo net. From the plots, the scatter of lineation orientation has been noted and the mean plunge direction has thus been obtained for each sample. The various stereo plots have been shown in figure 3 . The lineation developed in each rock specimen has been found to show varying

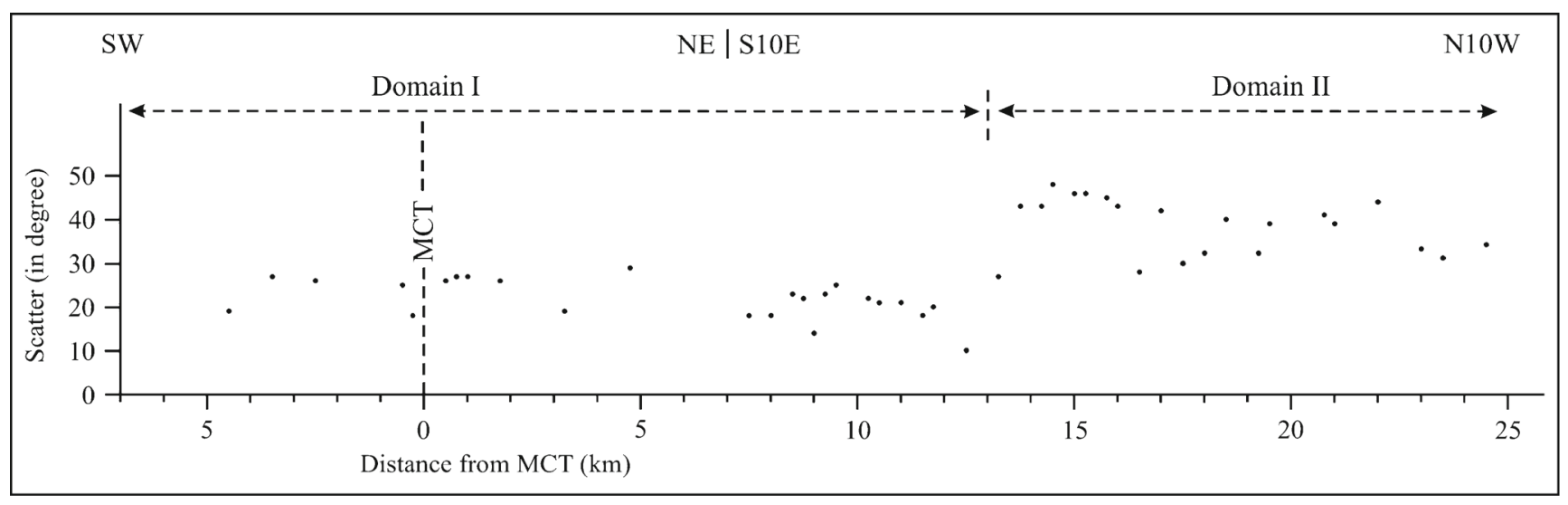

Figure 4. Scatter-distance diagram showing the scatter of lineation orientation with respect to the distance from the MCT (in both the crystalline zone as well as in the sedimentary belt). 
Table 1. Showing the direction and amount of plunge of lineation in the rocks of the area with respect to the distance from the MCT.

\begin{tabular}{|c|c|c|c|c|c|c|c|}
\hline \multirow[b]{2}{*}{ SI. no. } & \multirow[b]{2}{*}{$\begin{array}{l}\text { Sample } \\
\text { no. }\end{array}$} & \multirow[b]{2}{*}{$\begin{array}{l}\text { Map distance from } \\
\text { MCT }(\mathrm{km})\end{array}$} & \multicolumn{2}{|c|}{$\begin{array}{l}\text { Orientation range of } \\
\text { plunge direction } \\
\text { (in degree) }\end{array}$} & \multirow[b]{2}{*}{$\begin{array}{c}\text { Scatter } \\
\text { (in degree) }\end{array}$} & \multirow[b]{2}{*}{$\begin{array}{c}\text { Mean plunge } \\
\text { orientation }\end{array}$} & \multirow[b]{2}{*}{ South } \\
\hline & & & From & To & & & \\
\hline 1 & DG-4 & 4.50 & 025 & 044 & 19 & $22 / 034$ & $\hat{i}$ \\
\hline 2 & DG-7 & 3.50 & 004 & 031 & 27 & $20 / 019$ & $\hat{\Xi}$ \\
\hline 3 & DG-11 & 2.50 & 347 & 013 & 26 & $38 / 359$ & $\stackrel{\bar{\Xi}}{\Xi}=$ \\
\hline 4 & GR-4 & 0.50 & 310 & 335 & 25 & $17 / 321$ & Z \\
\hline 5 & GR-6 & 0.25 & 342 & 000 & 18 & $20 / 353$ & $i$ \\
\hline-- & ------ & ------- & - - МCT- & --- & ---- & ----- & $-7--$ \\
\hline 6 & RMu-2 & 0.50 & 020 & 046 & 26 & $19 / 035$ & $\hat{i}$ \\
\hline 7 & RMu-4 & 0.75 & 020 & 047 & 27 & $33 / 033$ & i \\
\hline 8 & RMu-5 & 1.00 & 006 & 033 & 27 & $17 / 016$ & I \\
\hline 9 & RMu-6 & 1.75 & 299 & 325 & 26 & $10 / 312$ & I \\
\hline 10 & RMu-12 & 3.25 & 000 & 019 & 19 & $21 / 009$ & 1 \\
\hline 11 & RMu-14 & 4.75 & 320 & 349 & 29 & $20 / 334$ & 1 \\
\hline 12 & MM-1 & 7.50 & 012 & 030 & 18 & $24 / 022$ & i \\
\hline 13 & MM-2 & 9.00 & 012 & 026 & 14 & $33 / 019$ & 1 \\
\hline 14 & MM-3 & 8.75 & 335 & 357 & 22 & $24 / 343$ & $\Xi$ \\
\hline 15 & MM-4 & 8.50 & 010 & 033 & 23 & $23 / 021$ & Еี \\
\hline 16 & MM-6 & 8.00 & 005 & 023 & 18 & $23 / 015$ & i \\
\hline 17 & JD-8 & 9.25 & 345 & 008 & 23 & $35 / 356$ & 1 \\
\hline 18 & JD-7 & 9.50 & 355 & 020 & 25 & $34 / 009$ & I \\
\hline 19 & JD-5 & 10.25 & 350 & 012 & 22 & $32 / 360$ & $\begin{array}{l}1 \\
0\end{array}$ \\
\hline 20 & JD-3 & 10.50 & 358 & 019 & 21 & $38 / 009$ & $\stackrel{\bar{N}}{N}$ \\
\hline 21 & JD-2 & 11.00 & 355 & 016 & 21 & $42 / 005$ & 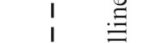 \\
\hline 22 & JD-1 & 11.50 & 010 & 028 & 18 & $30 / 019$ & $\frac{\pi}{3}$ \\
\hline 23 & JL-1 & 11.75 & 000 & 020 & 20 & $26 / 012$ & $\underline{-}$ \\
\hline 24 & JL-3 & 12.50 & 328 & 338 & 10 & $07 / 334$ & $\stackrel{\tilde{E}}{=}$ \\
\hline$-\overline{25}$ & $--\overline{\mathrm{LS}-1}$ & $\overline{13} . \overline{25}$ & $\overline{3} 4 \overline{3}$ & $\overline{010}$ & -27 & $3 \overline{2} / 3 \overline{5} 8$ & $\overline{4}$ \\
\hline 26 & LS-3 & 13.75 & 321 & 004 & 43 & $57 / 339$ & i \\
\hline 27 & LS-4 & 14.25 & 336 & 019 & 43 & $37 / 357$ & i \\
\hline 28 & LS-5 & 14.50 & 307 & 355 & 48 & $32 / 331$ & 1 \\
\hline 29 & LS-6 & 15.00 & 309 & 355 & 46 & $55 / 335$ & 1 \\
\hline 30 & LS-8 & 15.75 & 305 & 350 & 45 & $54 / 329$ & 1 \\
\hline 31 & LS-11 & 15.25 & 330 & 016 & 46 & $33 / 359$ & 1 \\
\hline 32 & SB-2a & 16.00 & 310 & 353 & 43 & $27 / 327$ & I \\
\hline 33 & SB-3 & 16.50 & 330 & 358 & 28 & $35 / 344$ & 1 \\
\hline 34 & SB-4 & 17.00 & 332 & 014 & 42 & $42 / 345$ & $\Xi$ \\
\hline 35 & SB-5 & 17.50 & 310 & 340 & 30 & $20 / 325$ & छ \\
\hline 36 & $\mathrm{BN}-1$ & 18.00 & 319 & 351 & 32 & $35 / 335$ & : \\
\hline 37 & $\mathrm{BN}-2 \mathrm{a}$ & 18.50 & 357 & 037 & 40 & $47 / 016$ & $i$ \\
\hline 38 & $\mathrm{BN}-3$ & 19.25 & 351 & 023 & 32 & $43 / 007$ & 1 \\
\hline 39 & $\mathrm{BN}-4$ & 19.50 & 330 & 009 & 39 & $46 / 346$ & I \\
\hline 40 & NM-2 & 20.75 & 343 & 024 & 41 & $44 / 358$ & 1 \\
\hline 41 & NM-3 & 21.00 & 333 & 012 & 39 & $31 / 352$ & 1 \\
\hline 42 & NM-5 & 22.00 & 341 & 025 & 44 & $53 / 007$ & I \\
\hline 43 & NM-8 & 23.00 & 015 & 048 & 33 & $30 / 033$ & I \\
\hline 44 & MR-1 & 23.50 & 300 & 331 & 31 & $22 / 315$ & \\
\hline 45 & MR-2 & 24.50 & 310 & 344 & 34 & $34 / 327$ & North \\
\hline
\end{tabular}


orientations in different parts of the specimen thus giving different azimuthal values for the lineations present in the specimen. The difference between the smallest and the highest azimuthal values has been noted for each specimen and this difference has been considered in this paper to represent the 'scatter' of lineation for that specimen. In order to understand the structural control of the lineation pattern, if any, the amount of scatter has been plotted against the distance of the samples from the trace of the MCT (scatter-distance plot) (figure 4).

In the area, the lineation in both the up-thrust and sub-thrust blocks typically shows northward plunge, varying from $15^{\circ}$ to $50^{\circ}$. In the vicinity of the MCT, however, the dominant lineation is given by stretched porphyroclasts, elongated trails of quartz, and quartzo-feldspathic minerals and this lineation has been assigned here as stretching lineation which is characteristic of Unit-I; it shows plunge of $15^{\circ}-40^{\circ}$ in the northern direction suggesting a dominant dip-slip component of movement (see figure 3). The stretching lineation progressively becomes stronger towards the trace of the MCT. We, therefore, consider the stretching lineation as characteristic of, and confined to, Unit I only. Within Unit-I, as mentioned above, the lineation scatter varies from $10^{\circ}$ to $27^{\circ}$. The lineation confined to the rocks of the higher units, on the other hand, has been assigned as mineral lineation and this lineation shows wider scatter of orientation than that of Unit-I (table 1).

\section{Discussion}

In the light of the above data and information, it appears that there is some control in the orientation of lineation in the vicinity of the MCT. In the higher horizons of the crystalline zone, the scatter of lineation orientation is high, up to $70^{\circ}$ and even more. Further southwards, i.e., towards the trace of the MCT, the scatter gradually falls down and shows a range of $27^{\circ}$ to $10^{\circ}$ in the vicinity of the MCT. The minor variations observed within the low-scatter zone in Domain-I could be linked to some variations in lithology, and hence rheological properties, of the rock types. In the sub-thrust block also, i.e., in the sedimentary belt, the scatter remains in the lower range, up to $27^{\circ}$ up to a distance of about $5 \mathrm{~km}$ from the trace of the MCT and further southwards in the sedimentary belt, the scatter gradually becomes higher. It is therefore apparent that within a distance of about $18-13 \mathrm{~km}$ in the crystalline rocks and $5 \mathrm{~km}$ in the sedimentary rocks - the scatter of lineation orientation is much lower as compared to higher scatter outside this zone in both the crystalline zone as well in the sedimentary belt. We assign this low scatter of lineation orientation to the presence of the MCT.

The MCT has been described as a ductile thrust developed at deeper levels of the crust (see Le Fort 1975; Bouchez and Pêcher 1981; Bhattacharya 1987; Bhattacharya and Weber 2004). The MCT had developed due to the India-Asia plate collision that resulted in the concentration of very high ductile shear strain at deeper levels. This triggered uplift/movement of a portion of the basement (crystalline) rocks along the MCT. Since the MCT is a crustal scale shear zone, a wide zone of rocks was affected by ductile shear deformation. As a result, a variety of thrust-related structural features were developed on both the up-thrust and sub-thrust rocks adjoining the MCT. It is therefore quite possible that the scatter of lineation was also controlled by the MCT shearing. We thus assign the entire tract with low scatter of lineation orientation to constitute a single domain, i.e., Domain-I or the MCT zone, and the tract away from this one as Domain-II.

It may be mentioned that in Domain-I, in addition to the stretching lineation (given by stretching of quartzo-feldspathic mineral aggregates and stretched trails of recrystallized quartz), occasionally the lineation is also shown by some other minerals such as muscovite, biotite, and hornblende. The latter minerals, on the other hand, show high scatter in Domain-II. It is therefore possible that with progressive shearing further southward, the mineral lineation of Domain II got rotated towards the bulk shear in the vicinity of the MCT. Mineral lineations $\left(\mathrm{L}_{2}\right)$ of Domain-I can thus be distinguished from those of Domain-II by their near-parallelism to each other (i.e., with low scatter) and their association with mylonites (products of shear zone), stretching lineation and a variety of shear-related structures and microstructures such as rotated porphyroclasts, S-C structures, shear bands, etc. Mineral lineations $\left(\mathrm{L}_{1}\right)$ of Domain-II, by contrast, are characterized by their high scatter, association with schistose rocks (not products of shear zone) and occur in rocks that are devoid of shear-related structures and microstructures.

The present work is based on field observations only and not on model experimental deformation. As such, the rotation of a line in response to shear zone shortening can at best be expressed by a conceptual model only, of which the Skjernaa (1980) model seems to be quite appropriate. It seems possible that during large scale shear movements along the MCT, as triggered by India-Asia plate collision, the extension of XY plane along X direction may have been associated with a sympathetic shortening along $\mathrm{Y}$ direction (assuming a constant-volume deformation). With progressive shear, therefore, the otherwise randomly oriented 
pre-shear lineations had developed a tendency to reorient themselves in the direction of bulk shear in order to keep them compatible, or in physical equilibrium, with the prevailing stress field. Likewise, with progressive shear the axes of several early-developed folds formed at high angles with the $\mathrm{X}$ direction may also have reoriented themselves towards the bulk shear. Unfortunately, the effect of local folding, that might have affected lineation dispersion, is not observed in the area. The reason is not clear; it may be due to some rheological constraints of the rocks or may also be due to the fact that several points of the area are inaccessible because of very rugged and difficult terrain. However, in other sectors of the MCT the effect of local folding has been observed (Bhattacharya and Siawal 1985; Bhattacharya 1987).

One more aspect needs consideration here. Considering the entire crystalline zone, the strike of foliation shows a change from NW to ENE. It is therefore possible that the direction of bulk shear kept on changing slightly with the advancement of the thrust mass. At this stage we link this perturbation to the undulations of the ground surface over which the thrust mass had moved. Considering all aspects together, it can therefore be said that in this part of the Himalaya the MCT played a great role in the reorientation of the linear features in its vicinity and the ground undulations during thrust movement may have controlled the minor variations in the direction of the bulk shear.

\section{Acknowledgements}

The authors thank the Head, Centre of Advanced Study in Geology, University of Lucknow, for providing the working facilities. AKV thanks the University Grants Commission for the award of a Rajiv Gandhi National Fellowship.

\section{References}

Aubourg C, Rochette P and Vialon P 1991 Subtle stretching lineation revealed by magnetic fabric of CallvianOxfordian black shales (French Alps); Tectonophys. 185 211-223.

Bell T H 1978 Progressive deformation and reorientation of fold axes in a ductile mylonite zone: The Woodroffe thrust; Tectonophys. 44 285-298.

Bhattacharya A R 1982 Geology of the Thal-Tejam-Girgaon area, Kumaun Himalaya, with special reference to the record of schuppen structures and measurement of flattening in folds; Geosci. J. 3(1) 27-42.

Bhattacharya A R 1987 A 'Ductile Thrust' in the Himalaya; Tectonophys. 135 37-45.

Bhattacharya A R and Siawal A 1985 A phenomenon of unusual flattening in folds associated with a Himalayan thrust; Geologie en Mijnbouw 64 159-165.

Bhattacharya A R and Weber K 2004 Fabric development during shear deformation in the Main Central Thrust zone, NW-Himalaya, India; Tectonophys. 387 23-48.

Brunel M 1986 Ductile thrusting in the Himalayas: Shear sense criterion and stretching lineations; Tectonics $\mathbf{5}$ 247-265.

Bouchez J-L and Pêcher A 1981 The Himalayan Main Central Thrust pile and its quartz-rich tectonites in central Nepal; Tectonophys. 78 23-50.

Gansser A 1964 Geology of the Himalayas; Interscience Publishers, London, 289p.

Griera A, Llorens M-G, Gomez-Rivas E, Bons P D, Jessel M W, Evans L A and Lebensohn R 2013 Numerical modelling of porphyroclasts and porphyroblast rotation in anisotropic rocks; Tectonophys. 587 4-29.

Heim A and Gansser A 1939 Central Himalayas, geological observations of the Swiss expedition 1936; Mem. Soc. Helv. Soc. Nat. 73(I) 1-245.

Le Fort P 1975 Himalayas, the collided range: Present knowledge of the continental arc; Am. J. Sci. 245A $1-44$.

Mandal N, Misra S and Samanta S K 2005 Rotation behaviour of rigid inclusions in multiple association: Insights from experimental and theoretical modals; $J$. Struct. Geol. 27 679-692.

Misra R C and Bhattacharya A R 1976 The Central Crystalline Zone of northern Kumaun Himalaya: Its lithostratigraphy, structure and tectonics with special reference to plate tectonics; Him. Geol. 6 133-154.

Moharana A, Mishra A and Srivastava D C 2013 Deformation style in the Munsiari Thrust Zone: A study in the Madlakia-Munsiari-Dhapa section in north-eastern Kumaun Himalaya; Int. J. Earth Sci. 102 1837-1849.

Patel R C and Kumar Y 2009 Deformation and structural analysis of the Higher Himalayan crystallines along Goriganga Valley, Kumaon Himalaya, India; In: Magmatism, Tectonism and Mineralization (ed.) Kumar S, Macmillan India Ltd., New Delhi, pp. 146-166.

Ramberg H and Ghosh S K 1977 Rotation and strain of linear and planar structures in three-dimensional progressive deformation; Tectonophys. 40 309-337.

Ridley J 1986 Parallel stretching lineations and fold axes oblique to a shear displacement direction a model and observations; Tectonophys. 8 647-665.

Sanderson D J and Marchini W R D 1984 Transpression; J. Struct. Geol. 6 449-458.

Schakleton R M and Ries A C 1984 The relation between regionally consistent stretching lineation and plate motions; J. Struct. Geol. 6 111-117.

Skjernaa L 1980 Rotation and deformation of randomaly oriented planar and linear structures in progressive simple shear; J. Struct. Geol. 2 101-109.

Twiss R J and Moores E M 1992 Structural Geology; W.H. Freeman and Company. 